\title{
Qualitative separation of the effect of voids on the static mechanical properties of hygrothermally conditioned carbon/epoxy composites
}

\author{
A. Y. Zhang ${ }^{1,2}$, D. H. Li ${ }^{1}$, D. X. Zhang ${ }^{1}$, H. B. Lu' ${ }^{1}$, H. Y. Xiao ${ }^{1}$, J. Jia $^{1}$ \\ ${ }^{1}$ Harbin Institute of Technology, 150001 Harbin, China \\ ${ }^{2}$ Harbin University, 150086 Harbin, China
}

Received 4 December 2010; accepted in revised form 22 February 2011

\begin{abstract}
The paper investigates the effect of voids and hygrothermal conditions on bending, compressive, and interlaminar shear strength (ILSS) of T300/914 composite laminates. By adopting different autoclave pressures during a cure cycle, specimens with three different void contents ranging from $0.33 \%$ to $1.50 \%$ were obtained. Experimental results reveal that compressive, bending strength, and ILSS decrease with increasing void contents and immersion time. The most significant decrease in strength of aged specimens is in the ILSS and compressive strength, followed by the bending strength. The effect of voids on the absorption/desorption behavior is also discussed. For a similar porosity, the compressive strength and ILSS of dried specimens are higher than that of the aged specimens, while they are lower than that of the unaged specimens. The bending strength of the dried specimens is higher than that of the unaged specimens. The experimental results are explained by the supportive micrographs that illustrate different types of voids and their morphology before and after moisture absorption/desorption.
\end{abstract}

Keywords: mechanical properties, laminates, porosity, moisture absorption, carbon fiber

\section{Introduction}

Manufacturing defects, particularly voids are among the most common manufacturing induced defects in composites [1, 2]. In polymeric composite materials, voids always have detrimental effects on the mechanical properties [3-5]. In general, voids have detrimental effects on the strength and fatigue life of composite laminates. Furthermore, voids cause a greater susceptibility to water penetration and environmental conditions [3].

Costa et al. [3] indicated that the ILSS values decreases with the void content of the carbon/epoxy laminates and carbon/BMI (bismaleimide) laminates. Chambers et al. [5] reported that increasing void content reduces both flexural strength and fatigue performance by acting both on the initiation and propagation stages of failure. de Almeida and Nogueira Neto [6] indicated that voids may cause a remarkable decrease in fatigue life despite having only a moderate influence on the static strength.

Composite aircraft structures are usually exposed to a range of hygrothermal conditions through their designed service life, which causes degradation in material properties of CFRP laminates. For polymer composites, moisture often causes swelling and degradation. The material degradation includes chemical changes of the matrix materials and debonding at the fiber/matrix interface. Long-term exposure at high temperatures is also a concern for CFRP, as higher temperatures accelerate diffusion rates of moisture and generally accelerate aging $[7,8]$.

\footnotetext{
${ }^{*}$ Corresponding author, e-mail: dongxingzhang@163.com (c) BME-PT
} 
Costa et al. [3, 9] indicated that voids in polymer matrix composites may result in significant reductions in matrix dominated mechanical properties such as interlaminar shear, compressive, and flexural strengths. Voids affect the same mechanical properties affected by environmental conditions. Costa et al. [3] also indicated that moisture absorption has been shown to lead to general reduction of the mechanical properties of composites. This has been attributed, in part, to the degradation of the fiber/matrix interfacial bond. Jedidi et al. [10] reported that polymer matrix composites undergo dimensional and stress state changes due to moisture induced swelling and thermal expansion in hygrothermal environment. Gigliotti et al. [11] indicated that temperature differentials and moisture absorption induce swelling in the material: then the heterogeneity of the hygrothermal fields and of the material are responsible for stress both at the micro and the macroscale. Cândido et al. [12] also reported that moisture absorption may induce mechanical and physical-chemical changes that toughen the polymeric matrix and/or deteriorate matrix/fiber by interfacial debonding or micro-cracking. The degradation of physical and mechanical properties has been found to depend primarily upon the total amount of moisture absorbed. Meziere et al. [13] reported that humidity has an influence on the fiber/matrix interface as well as the matrix properties. The behavior of any composite depends on the efficiency of the fiber/matrix interface which can be reduced by the presence of water.

As described above, many previous literatures have studied the effect of voids on the mechanical strength of unidirectional fiber composite materials under hygrothermal conditions. However, studies evaluating the mechanical performance of woven carbon/epoxy laminates under moisture absorption/desorption conditions are scarce.

This research was aimed to characterize the voids in woven carbon fiber materials and to investigate the effect of void content on compressive, bending, and interlaminar shear strength (ILSS) of T300/914 laminates that are kept at room temperature, hygrothermal, and dry environments, respectively. In this paper, a series of experiments was carried out to study the effects of void content on the hygrothermal and desorption behaviors of carbon/epoxy laminates.

\section{Experimental \\ 2.1. Raw materials and specimens preparation}

The specimens were fabricated from commercially available (Hexcel Composites Ltd., Stamford,CT, USA) carbon/epoxy pre-impregnated tapes. The tapes were made of T300 carbon fibers pre-impregnated with Hexcel 914 epoxy resin (fiber volume fraction of $58 \%$ ). The material was laid up by hand in $270 \mathrm{~mm} \times 300 \mathrm{~mm}$ woven laminates $\left[( \pm 45)_{4} /\right.$ $\left.(0,90) /( \pm 45)_{2}\right]_{\mathrm{S}}$. Each laid-up stack was fit into a vacuum bag and placed in an autoclave for curing. The laminates were cured with a ramp of $1.5^{\circ} \mathrm{C} / \mathrm{min}$ from room temperature to $135^{\circ} \mathrm{C}$, and then held at $135^{\circ} \mathrm{C}$ for $0.5 \mathrm{~h}$ prior to being ramped to $180^{\circ} \mathrm{C}$ at $1.5^{\circ} \mathrm{C} / \mathrm{min}$. The laminates were further held at $180^{\circ} \mathrm{C}$ for $2.5 \mathrm{~h}$. Finally, they were ramped to $45^{\circ} \mathrm{C}$ to produce the final composite laminates. In addition, each step was conducted in a vacuum bag of $0.06 \mathrm{MPa}$.

Using the described procedure to produce the compressive, bending, and ILSS samples, specimens with three different porosity levels ranging from 0.33 to $1.50 \%$ were obtained by employing autoclave pressures of $0.4,0.2$ and $0.0 \mathrm{MPa}$.

An experimental program to characterize the effect of voids on the strength of T300/914 laminates was presented. Three conditions were used in this study: (a) ambient conditions: the specimens were kept at room temperature, defined as unaged specimens; (b) hygrothermal conditions: the specimens were dried in an oven at $70^{\circ} \mathrm{C}$ until their weights were stabilized and then (the now engineering dry specimens) were immersed in distilled water at $70^{\circ} \mathrm{C}$ until reaching a saturated moisture content, defined as aged specimens; and (c) dried conditions: the aged specimens were dried in an oven at $70^{\circ} \mathrm{C}$ until reaching equilibrium, defined as dried specimens.

\subsection{Morphology and structure observation}

The distribution, shape, and location of voids in the unaged and aged laminates were observed with a metallurgical microscope (VNT-100, Visual New Technology Developing Co., Ltd, Beijing, China). The specimens were carefully prepared for microstructural analysis using a polishing regime beginning with grade silicon carbide abrasive paper, and ending with $1 \mu \mathrm{m}$ diamond paste. The microscope was then used to analyze the pore morphology. 
A scanning electron microscopy (SEM) STERED SCAN-240 (Sonatest Ltd, UK) was used to study the effect of moisture absorption on the microstructure of the water-immersed composite specimens. The fractographic examinations were carried out in detail on the compressive, bending, and ILSS fracture surfaces of specimens before and after moisture absorption.

\subsection{Moisture absorption test procedure}

Moisture absorption tests were carried out according to Chinese standard HB 7401-96. Prior to the moisture tests, all specimens were dried in an oven at $70^{\circ} \mathrm{C}$ until their weight became stable. The engineering dry specimens were immersed in distilled water at $70^{\circ} \mathrm{C}$ until reaching saturated moisture content. The change in weight of each specimen was measured as a function of immersion time. The specimen were removed from the water bath at regular intervals, wiped with filter paper to remove surface water, and then cooled back to room temperature before recording the weight and being placed back into water bath. The water content in the specimen was measured by the difference in weight throughout the moisture tests.

\subsection{Mechanical tests}

The compressive strength of T300/914 composite laminates was measured with an Instron 5582 mechanical testing machine (U.S. INSTRON Company, Norwood, MA, U.S.) in accordance with the Chinese standard GB/T3856-2005 procedure at a crosshead speed of $2 \mathrm{~mm} / \mathrm{min}$. The length, width, and the thickness of the compressive specimen were approximately $140,6,4.5 \mathrm{~mm}$, respectively. Two different porosity levels ranging from 0.33 to $1.50 \%$ were obtained for the compressive specimen.

The three-point bending tests were performed with the MTS-810 multi-purpose machine in accordance with the Chinese standard GB/T3356-1999 at a loading rate of $5 \mathrm{~mm} / \mathrm{min}$. The rectangular specimens had the dimensions of $90 \mathrm{~mm} \times 25 \mathrm{~mm} \times$ $4.5 \mathrm{~mm}$, where the span is $72 \mathrm{~mm}$. Two different porosity levels ranging from 0.33 to $1.50 \%$ were obtained for the bending specimen.

The ILSS strength of the T300/914 composite laminates was measured with an Instron 5582 mechanical testing machine in accordance with the Chinese standard GB/T1450.1-2005 procedure at a crosshead speed of $2 \mathrm{~mm} / \mathrm{min}$. The rectangular specimens have the dimensions of $33 \mathrm{~mm} \times 6 \mathrm{~mm} \times 4.5 \mathrm{~mm}$, with a span-to-thickness ratio of 5 . Three different porosity levels ranging of $0.33,0.71$ and $1.50 \%$ were obtained for the ILSS specimen.

For statistical purposes, a total of five samples per condition were tested.

\section{Results and discussion \\ 3.1. Pore morphology analysis}

A metallurgical microscope provides an excellent technique for examining the distribution, shape, and location of voids in the composite specimens. It is expected that the surface morphology of the moisture absorbed composite specimen will be different from that of dry composite specimens, particularly in terms of voids, porosity, swelling, sorption in micro-cracking, and disbanding around filler. The pores can act as stress concentration points, and lead to premature failure of the composites during loading. Therefore, studies of the composite surface topography provide vital information on the level of interfacial adhesion that exists between the fiber and matrix when used as reinforcement in wet conditions [14].

Figure 1 shows the microstructural morphology of voids in the carbon/epoxy laminate which was kept at room temperature. As shown in Figure 1a) and b), where the porosity ranged from 0.33 to $0.71 \%$, the typically spherical voids were mostly, and preferentially located at the resin rich areas. As shown in Figure 1c), when porosity increased to $1.50 \%$, elongated or elliptical voids appeared in the resin along the fiber/matrix interface. Some voids were typically located at the crossing of the woven fiber tows, therefore having a triangular shape within the resin rich areas. It could be seen that the larger voids tended to be relatively aligned in the fiber direction.

Figure 2 illustrates the pore morphology of the aged specimens. As shown in Figure 2a), when the porosity is $0.33 \%$, the aged specimens present minor cracks from the fiber/matrix interface. Figure 2b) and c) show that matrix cracks and interlaminar cracks emanate from the void, and propagate longitudinally along the fiber/matrix interface. Damage evolution of the aged specimen was primarily caused by the debonding of the fiber/matrix inter- 


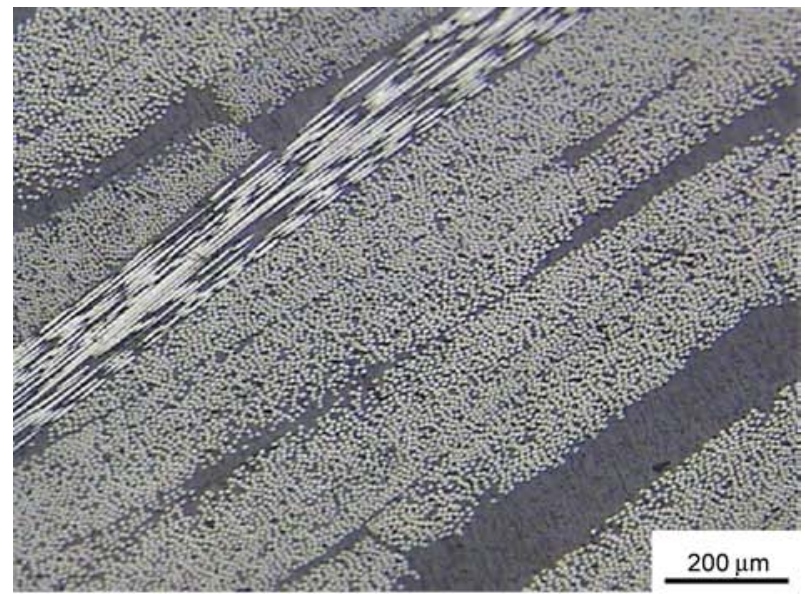

a)

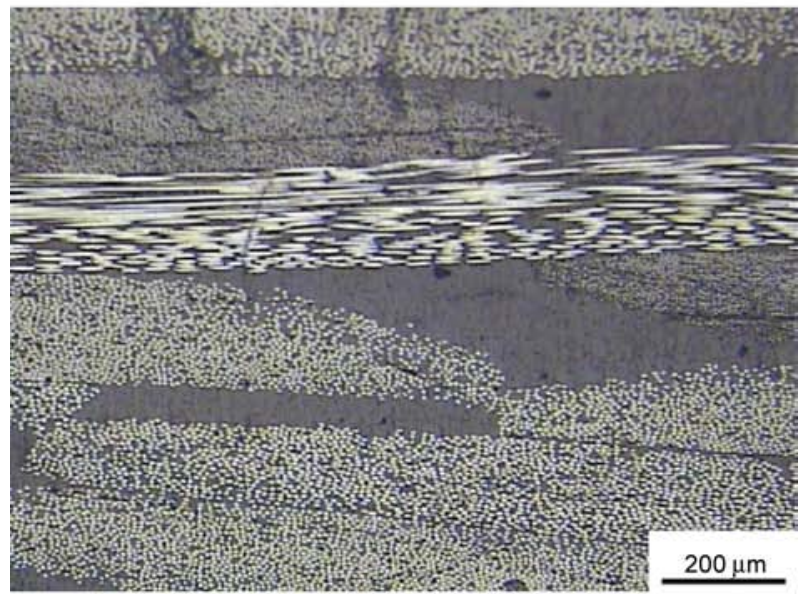

b)
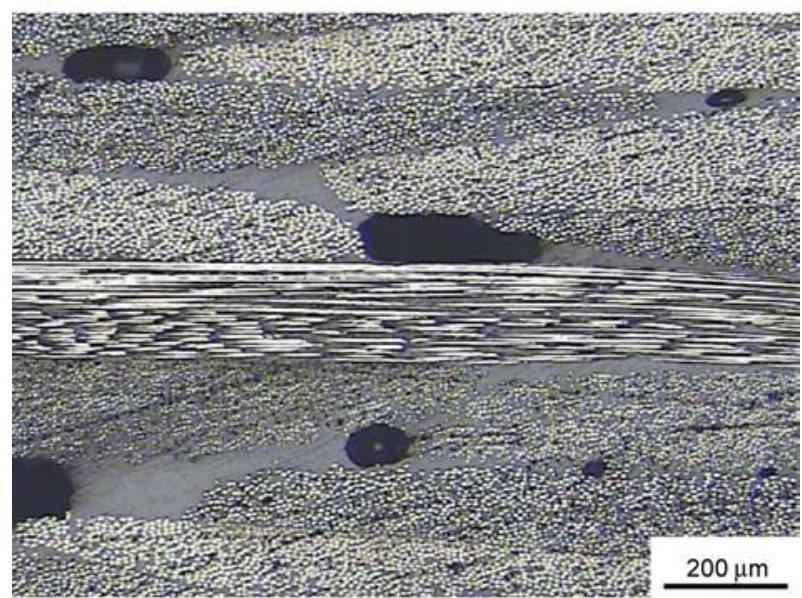

c)

Figure 1. Morphology and structure of the unaged specimens with different void content. a) Porosity of $0.33 \%$, b) porosity of $0.71 \%$, c) porosity of $1.50 \%$.

face. Voids could potentially amplify the effects of moisture absorption in the laminate, and introduce high stress concentrations that facilitate the development of microcracks [9]. Moisture absorption accelerates the damage propagation in the compos-

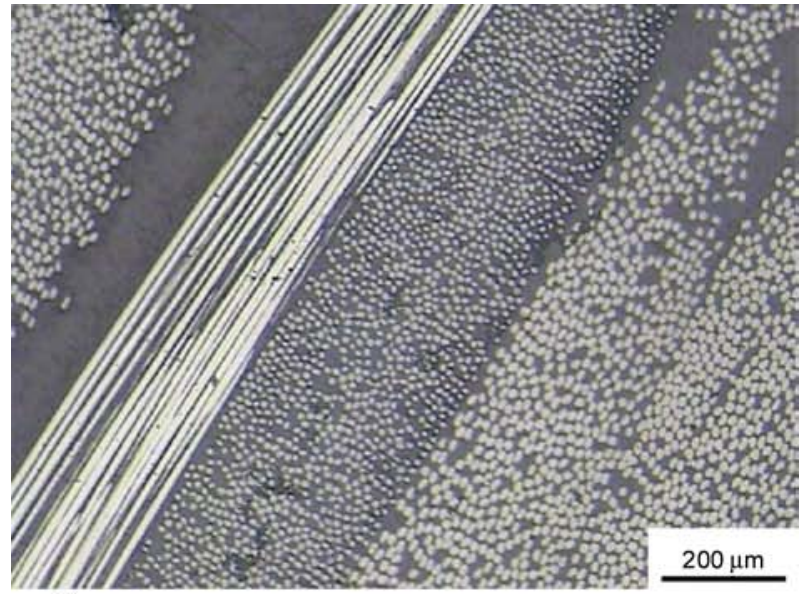

a)

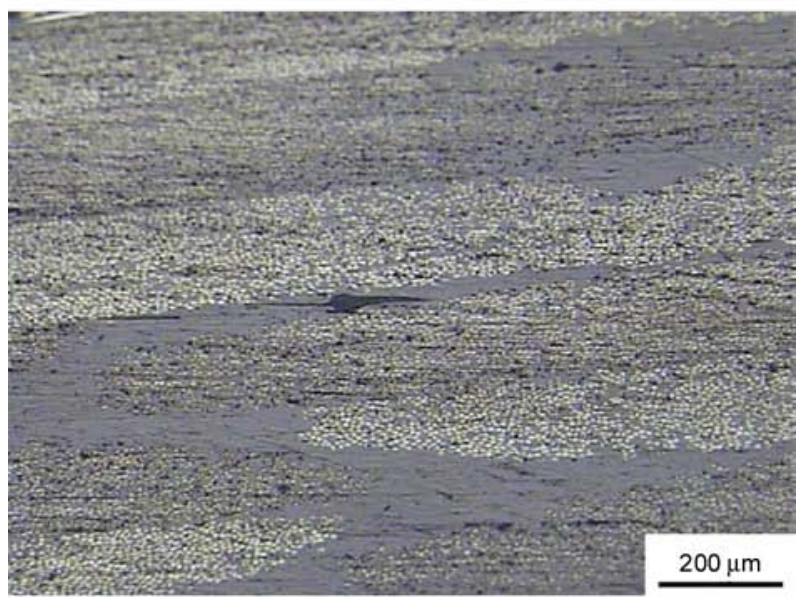

b)

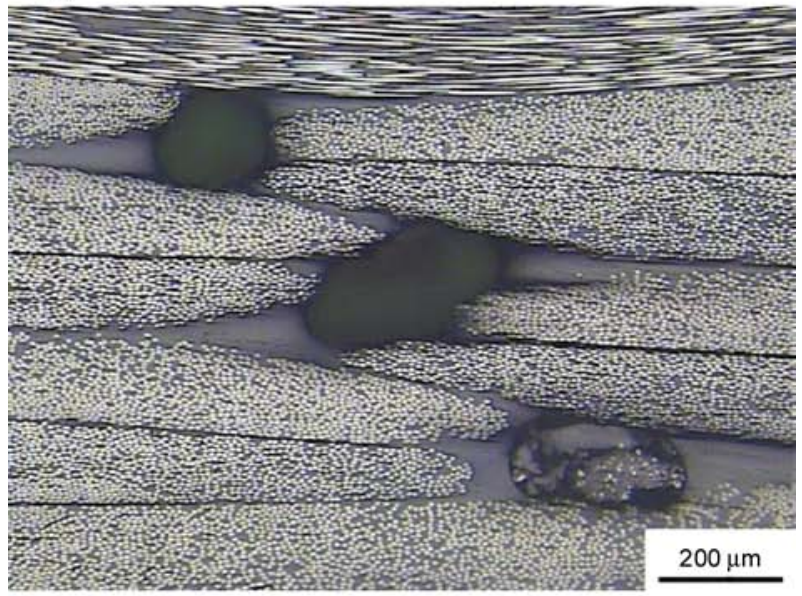

c)

Figure 2. Pore morphology of the aged specimens with different porosity. a) Porosity of $0.33 \%$, b) porosity of $0.71 \%, c)$ porosity of $1.50 \%$.

ite. With the same porosity, a greater number of matrix cracks and interfacial cracks were observed in the aged specimens in comparison to the unaged specimens (as shown in Figure 1). 


\subsection{Compressive strength test}

The presence of moisture within polymeric composites often degrades their physical and mechanical properties $[12,15]$. As shown in Figure 3, with the porosity increasing from 0.33 to $1.50 \%$, the compressive strength of unaged and aged specimens decreased 4.3 and $10.8 \%$, respectively. Compared with the unaged specimens, the compressive strength of aged specimens decreased 14.6 and $20.4 \%$, with respective porosities of 0.33 and $1.50 \%$, respectively.

A compressive test is principally driven by the behavior of the resin and the fiber/matrix interfaces, especially in hygrothermal aging conditions. Costa et al. [9] indicated that the water absorbed by the laminates causes either reversible or irreversible plasticization of the matrix. Combined with the temperature effects, these factors may cause significant changes in the matrix toughness, affecting the laminate strength. These factors reduce the load transfer capacity of the interface.

Figure 4 shows the compression fractures of fiber, interfacial cracks, and fiber buckling, leading to an irregular, 'stepped' fracture surface. This is a characteristic feature of compression failure.

As shown in Figure 5, the general trend of the compressive strength decreased with increasing porosity, and the compressive strength of dried specimens was higher than that of aged specimens in the case of similar porosity. The water absorbed by the laminates caused reversible swelling and a plasticization effect on the matrix, which was usually recoverable after drying.

Compared to unaged specimens, the compressive strength retention of the dried specimens were 90.4 and $81.6 \%$ with a porosity of 0.33 and $1.50 \%$, respec-

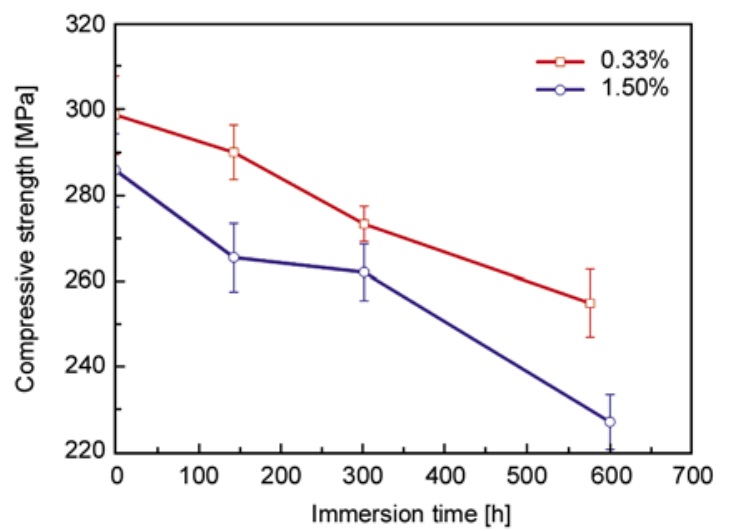

Figure 3. Compressive strength curves of the aged specimens with different porosity tively. The compressive strength of the dried specimens was lower than that of the unaged specimens for the same porosity. Water absorption in the laminates, combined with external or internal stresses (caused by loading or thermo-elastic effects), instigated crack propagation and hydrolysis in the resin

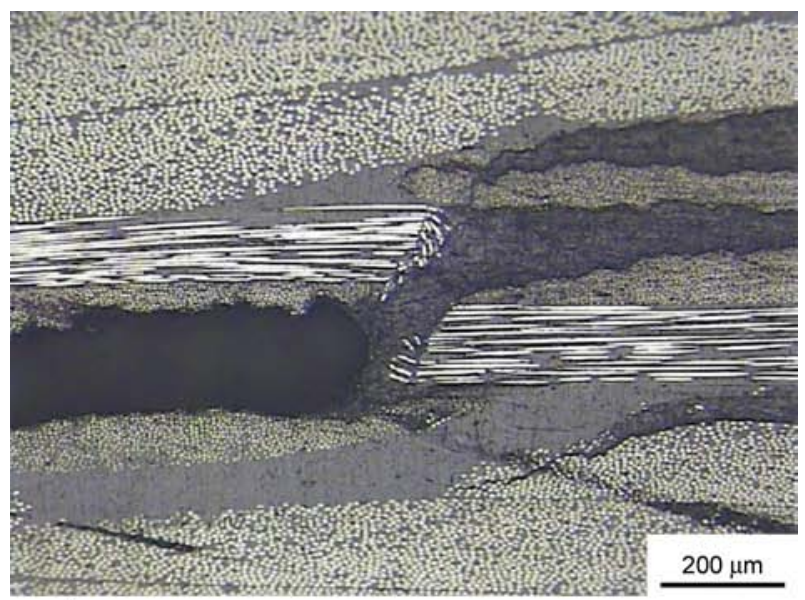

a)

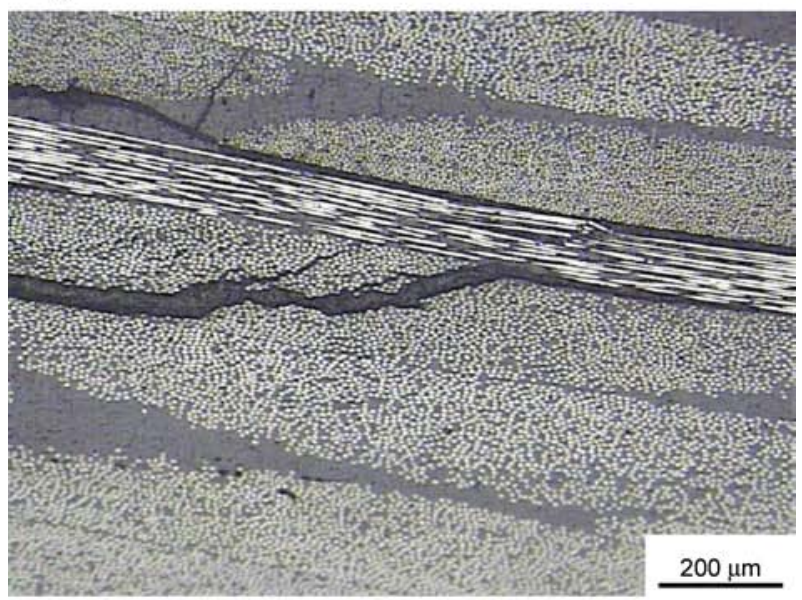

b)

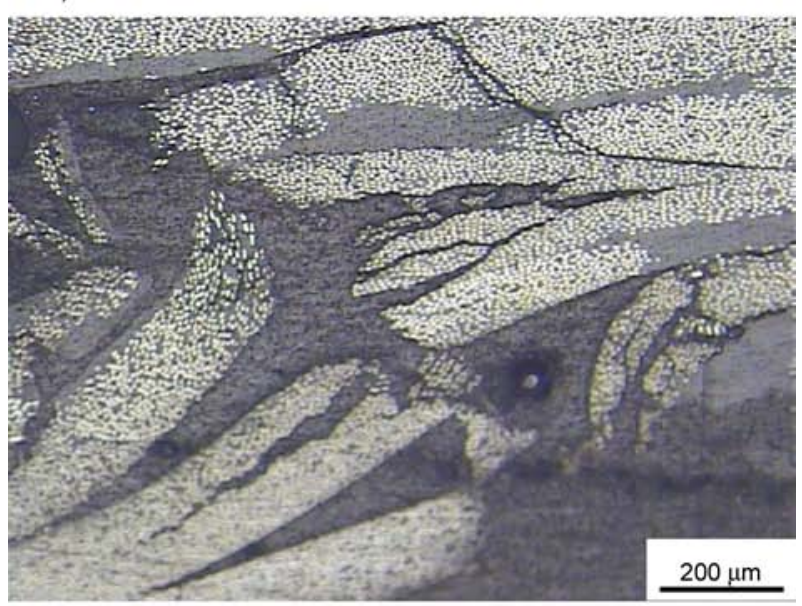

c)

Figure 4. Pore morphology of the aged compressive specimens. a) Fiber compressive fractures, b) interfacial cracks, c) fiber buckling. 


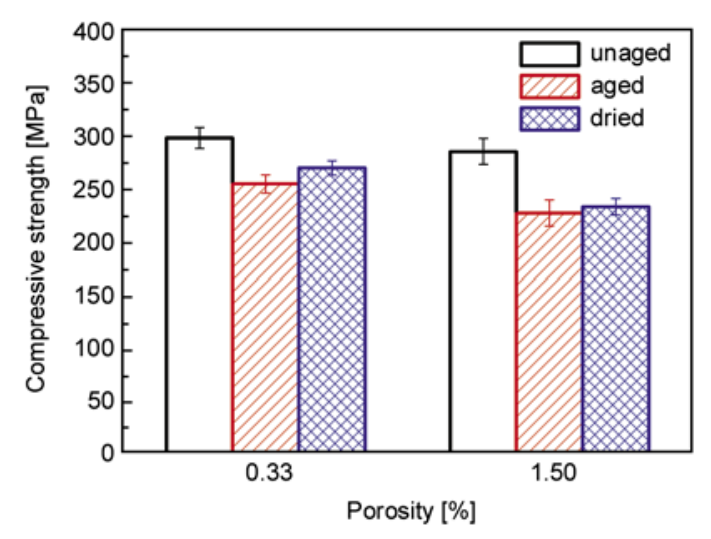

Figure 5. Compressive strength in different conditions of different porosity

matrix. The composite undergoes permanent weakening and its strength cannot be recovered after drying.

\subsection{Bending strength test}

As shown in Figure 6, with the porosity increasing from 0.33 to $1.50 \%$, the bending strength of unaged

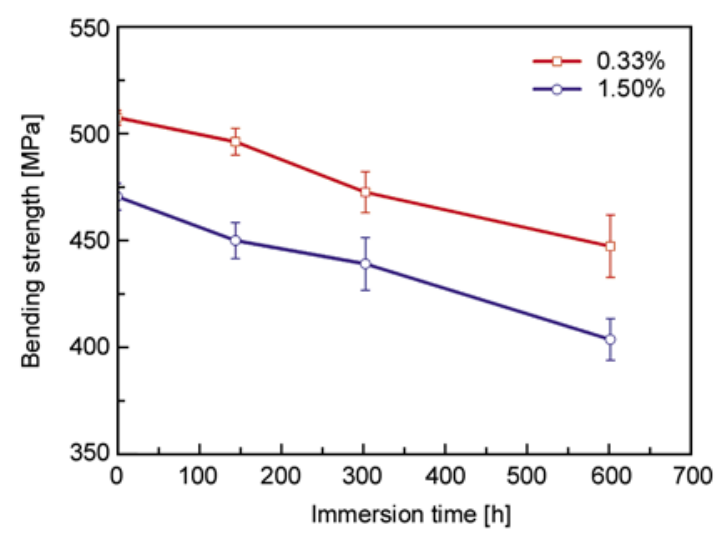

Figure 6. Bending strength curves of the aged specimens with different porosity

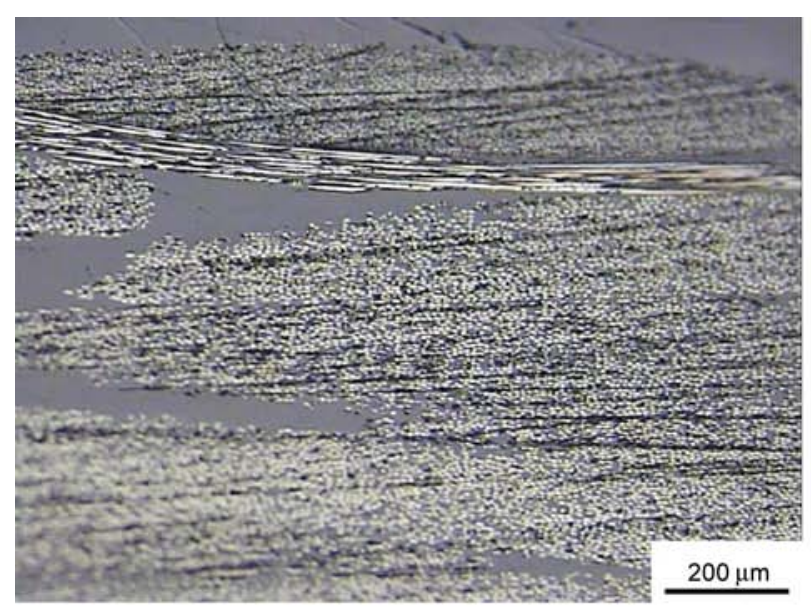

a) and aged specimens decreased 7.2 and $9.8 \%$, respectively. The reduction in net section combined with the increase in void content had a detrimental effect on strength.

Compared to the unaged specimens, the bending strength of the aged specimens decreased 11.8 and $14.2 \%$ with porosity of 0.33 and $1.50 \%$, respectively. Water absorption and its resulting effects contribute to the loss of compatibility between the fibers and matrix, which resulted in debonding and weakening of the interfacial adhesion [16]. The interface and the effects of environmental conditions on its strength play a major role in determining the strength of composite laminates in the presence of moisture [9].

Figure 7 illustrates that the damage of the tensile side of the aged failed bending specimens was more severe than that of the compressive side. Matrix cracks, fiber breakage and the interfacial cracks were observed in the tensile side of the aged failed bending specimens.

The delamination and cracks act like pores, which allow the further diffusion of water and chemicals and causes degradation. The delamination and cracks in the matrix weaken the load transfer between the fibers, and additional harmful chemicals diffuse to the interface between the fiber and matrix. Consequently, the interface between the fiber and matrix is weakened, reducing the mechanical performance [17].

Figure 8 shows that the bending strength of the aged specimens was lower than that of the unaged specimens for similar porosity. This could be due to the fact that the immersion of composites specimens at

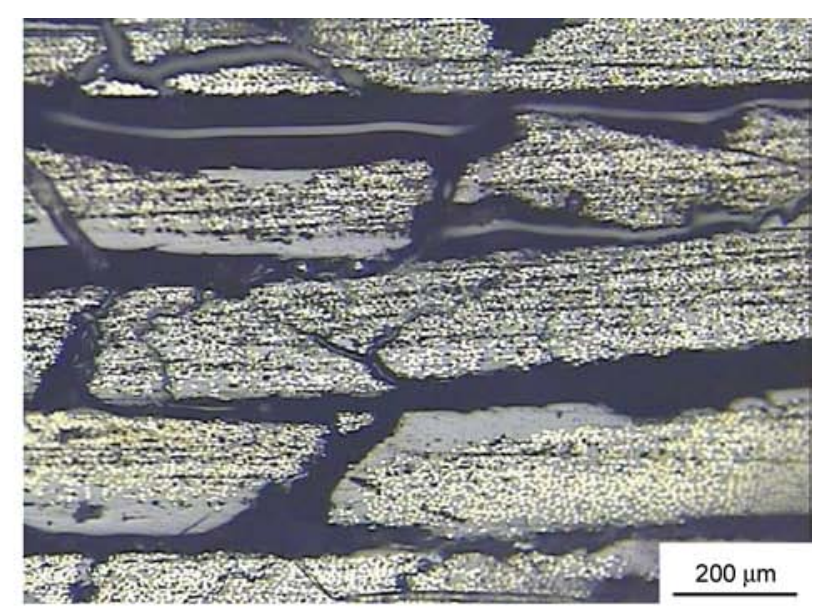

b)

Figure 7. Micrographs of the aged failed bending specimens. a) Compressive side, b) tensile side 


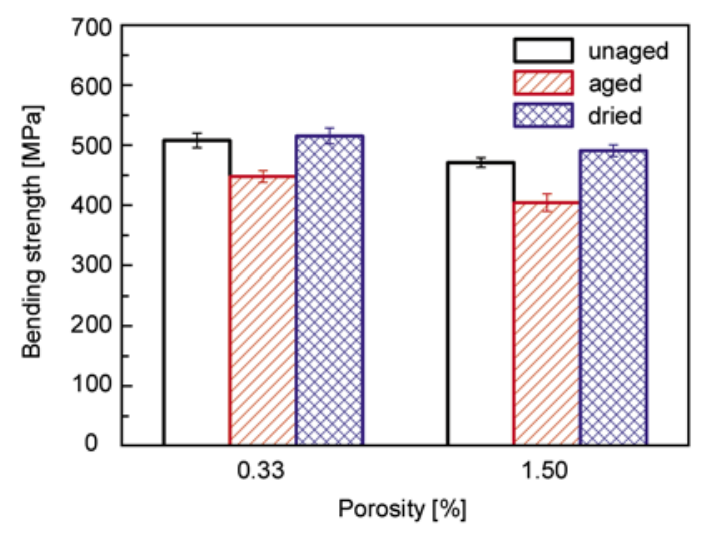

Figure 8. Bending strength in different conditions of different porosity

water affected the interfacial adhesion between the fiber and matrix and created the debonding leading to a decrease in the mechanical properties of the composites. As shown in Figure 8, the general trend of the bending strength of dried specimens decreased with the increase of porosity. Furthermore, the bending strength of dried specimens was higher than that of the unaged specimens for similar porosity. This may be due to the dry conditions leading to an increase of the curing degree, which eliminated some of the residual stress and improved the adhesion of the fiber/matrix interface.

\subsection{ILSS test}

As seen in Figure 9, with the porosity increasing from 0.33 to $1.50 \%$, the ILSS of the unaged and aged specimens decreased 8.6 and $26.2 \%$, respectively. Compared to the unaged specimens, the interlaminar shear strength of the corresponding aged

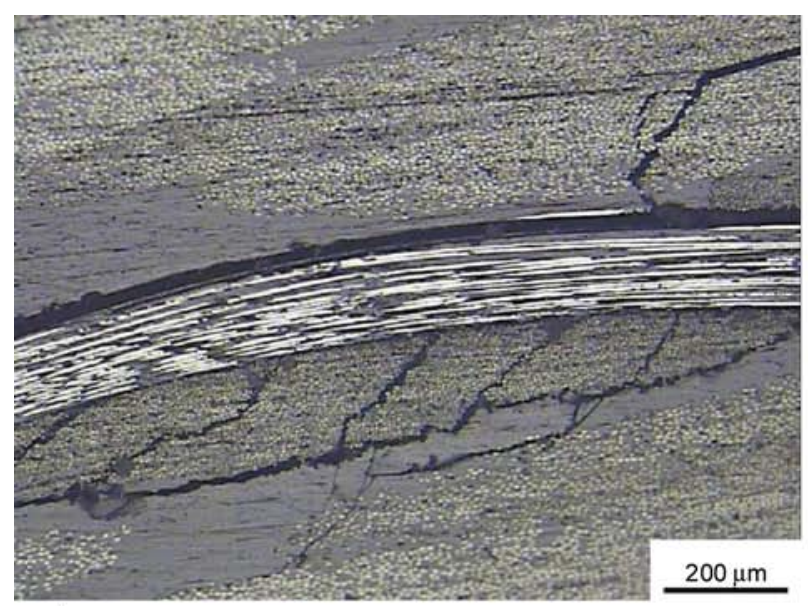

a)

Figure 10. Pore morphology of the aged ILSS failed specimens with different porosity. a) Porosity of $0.33 \%$, b) porosity of $1.50 \%$.

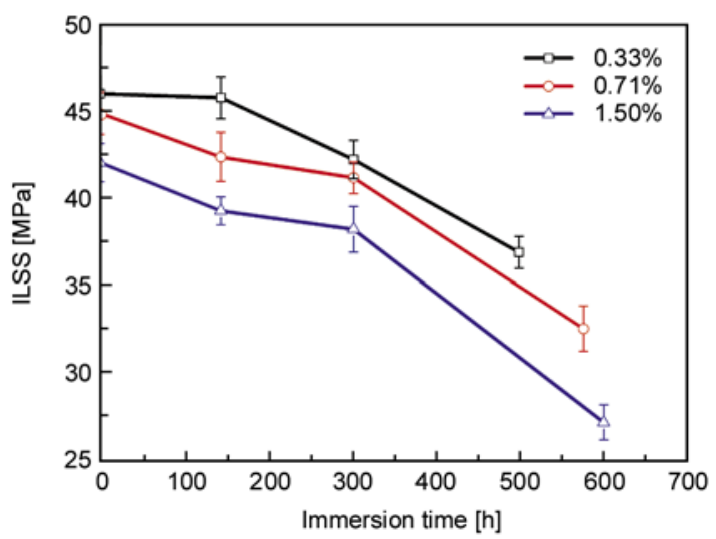

Figure 9. ILSS curves of the aged specimens with different porosity

specimens decreased $19.7,27.4$, and $35.2 \%$ with porosity of $0.33,0.71$, and $1.50 \%$, respectively.

It is observed in Figure 9 that ILSS dropped incrementally in hygrothermal conditions as immersion time increased. Moisture absorption and high temperature cause plasticization of the matrix which changes its toughness. Moreover, humidity and temperature cause dimensional changes and induce stresses in the laminate that degrade the fiber/ matrix interface [9]. The ILSS test is principally driven by the behavior of the resin and the fiber/ matrix interfaces, which are particularly affected by hygrothermal aging. As shown in Figure 9, the ILSS of aged specimens indeed decreases with the immersion time.

Figure 10a shows that matrix cracks, interlaminar cracks, and further crack propagation were observed in the aged ILSS failure specimens with a porosity of $0.33 \%$. As shown in Figure 10b, an apparent

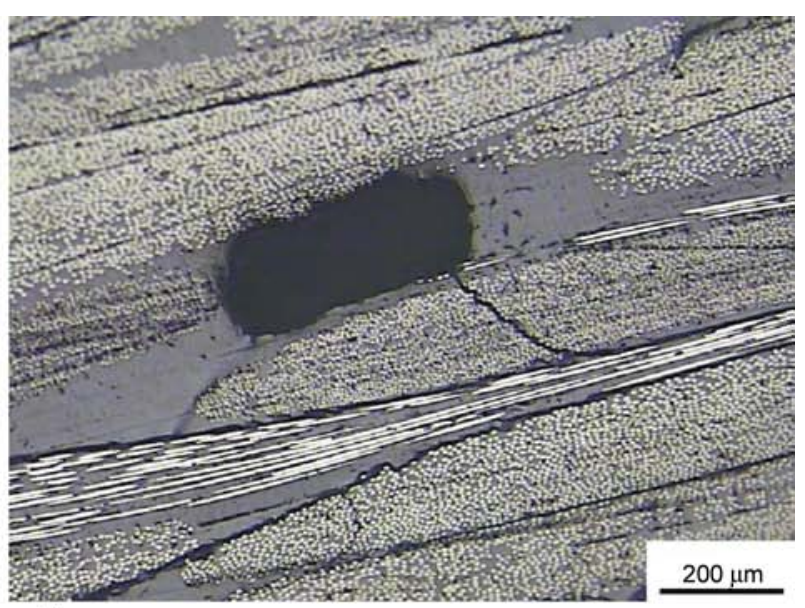

b) 


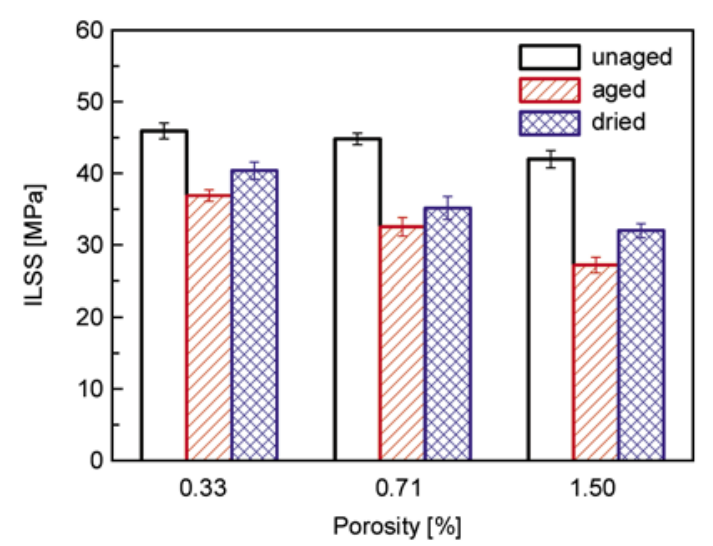

Figure 11. ILSS in different conditions of different porosity

matrix crack was initiated from a void and extended to the fiber/matrix interface in the aged ILSS failure specimens with a porosity of $1.50 \%$.

A decrease in the ILSS with increasing porosity was observed for all the T300/914 laminates in Figure 11. Compared to the unaged specimens, the ILSS retention of dried specimens was 87.9, 78.5, and $76.3 \%$ with porosities of $0.33,0.71$, and $1.50 \%$, respectively. For the same porosity, the ILSS of dried specimens was lower than that of the unaged specimens but higher than that of the aged specimens for similar porosity.

\section{Conclusions}

A series of experiments were conducted to separate qualitatively the effect of voids on the static mechanical properties of hygrothermal conditioned carbon/epoxy composites. Through systematic investigation, there were three conclusions to be drawn. (1) Moisture absorption led to an acceleration of damage to the composite. For similar porosity, a higher concentration of matrix crack and interfacial crack were observed in the aged specimens than in the unaged specimens. (2) The general trend of the compressive, bending, and interlaminar strength of the unaged, aged and dried specimens decreased with the increase of porosity and immersion time. The most significant decrement in the strength of the aged specimens was in the ILSS and compressive strength, with the reduction of the bending strength being less prominent. The ILSS and compressive strength tests were principally driven by the behavior of the resin and the fiber/matrix interfaces, which are particularly affected by hygrother- mal aging. (3) For similar porosity, the compressive strength and ILSS of the dried specimens was higher than that of the aged specimens, but lower than that of the unaged specimens. However, the bending strength of the dried specimens was higher than that of the unaged specimens.

\section{Acknowledgements}

The authors are gratefully to the Harbin Aircraft Industry Group for supporting this work.

\section{References}

[1] Puglia P. D., Sheikh M. A., Hayhurstb D. R.: Classification and quantification of initial porosity in a CMC laminate. Composites Part A: Applied Science and Manufacturing, 35, 223-230 (2004).

DOI: $10.1016 /$ j.compositesa.2003.09.026

[2] Birt E. A., Smith R. A.: A review of NDE Methods for porosity measurement in fiber-reinforced polymer composites. Non-Destructive Testing and Condition Monitoring, 46, 681-686 (2004).

[3] Costa M. L., de Almeida S. F. M., Rezende M. C.: The influence of porosity on the interlaminar shear strength of carbon/epoxy and carbon/bismaleimide fabric laminates. Composites Science and Technology, 61, 21012108 (2001). DOI: $10.1016 / \mathrm{S} 0266-3538(01) 00157-9$

[4] Wisnom M. R., Reynolds T., Gwilliam N.: Reduction in interlaminar shear strength by discrete and distributed voids. Composites Science and Technology, 56, 93-101 (1996). DOI: $10.1016 / 0266-3538(95) 00128-\mathrm{X}$

[5] Chambers A. R., Earl J. S., Squires C. A., Suhot M. A.: The effect of voids on the flexural fatigue performance of unidirectional carbon fibre composites developed for wind turbine applications. International Journal of Fatigue, 28, 1389-1398 (2006). DOI: $10.1016 /$ j.ijfatigue.2006.02.033

[6] de Almeida S. F. M., Nogueira Neto Z. S.: Effect of void content on the strength of composite laminates. Composite Structure, 28, 139-148 (1994).

DOI: 10.1016/0263-8223(94)90044-2

[7] Aokia Y., Yamada K., Ishikawa T.: Effect of hygrothermal condition on compression after impact strength of CFRP laminates. Composites Science and Technology, 68, 1376-1383 (2008).

DOI: 10.1016/j.compscitech.2007.11.015

[8] Tsai Y. I., Bosze E. J., Barjasteh E., Nutt S. R.: Influence of hygrothermal environment on thermal and mechanical properties of carbon fiber/fiberglass hybrid composites. Composites Science and Technology, 69, 432-437 (2009).

DOI: $\underline{10.1016 / \text { j.compscitech.2008.11.012 }}$ 
[9] Costa M. L., Rezende M. C., de Almeida S. F. M.: Strength of hygrothermally conditioned polymer composites with voids. Journal of Composite Materials, 39, 1943-1961 (2005).

DOI: $10.1177 / 0021998305051807$

[10] Jedidi J., Jacquemin F., Vautrin A.: Design of accelerated hygrothermal cycles on polymer matrix composites in the case of a supersonic aircraft. Composite Structure, 68, 429-437 (2005).

DOI: $10.1016 /$ j.compstruct.2004.04.009

[11] Gigliotti M., Jacquemin F., Molimard J., Vautrin A.: Transient and cyclical hygrothermoelastic stress in laminated composite plates: Modelling and experimental assessment. Mechanics of Materials, 39, 729745 (2007).

DOI: 10.1016/j.mechmat.2006.12.006

[12] Cândido G. M., Costa M. L., Rezende M. C., Almeida S. F. M.: Hygrothermal effects on quasi-isotropic carbon epoxy laminates with machined and molded edges. Composites Part B: Engineering, 39, 490-496 (2008). DOI: 10.1016/j.compositesb.2007.03.007

[13] Meziere Y., Bunsell A. R., Favry Y., Teissedrea J-C., Do A. T.: Large strain cyclic fatigue testing of unidirectional carbon fibre reinforced epoxy resin. Composites Part A: Applied Science and Manufacturing, 36, 1627-1636 (2005).

DOI: $10.1016 /$ j.compositesa.2005.03.020
[14] Athijayamani A., Thiruchitrambalam M., Natarajan U., Pazhanivel B.: Effect of moisture absorption on the mechanical properties of randomly oriented natural fibers/polyester hybrid composite. Materials Science and Engineering: A, 517, 344-353 (2009).

DOI: $10.1016 /$ j.msea.2009.04.027

[15] Costa M. L., Rezende M. C., de Almeida S. F. M.: Effect of void content on the moisture absorption in polymeric composites. Polymer-Plastics Technology and Engineering, 45, 691-698 (2006).

DOI: $10.1080 / 03602550600609549$

[16] Kim H. J., Seo D. W.: Effect of water absorption fatigue on mechanical properties of sisal textile-reinforced composites. International Journal of Fatigue, 28, 1307-1314 (2006).

DOI: $10.1016 /$ j.ijfatigue.2006.02.018

[17] Won J-P., Lee S-J., Kim Y-J., Jang C-I., Lee S-W.: The effect of exposure to alkaline solution and water on the strength-porosity relationship of GFRP rebar. Composites Part B: Engineering, 39, 764-772 (2008). DOI: 10.1016/j.compositesb.2007.11.002 